\title{
Who Is Democracy Good For? Elections, Rural Bias, and Health and Education Outcomes in Sub-Saharan Africa
}

\author{
Robin Harding, University of Oxford
}

How do African governments respond to democratic electoral competition? Although the common perception is that African governments have sought to win elections by combining various types of electoral fraud, clientelism, and ethnic mobilization, I argue that democratic elections in Africa have also induced governments to compete for votes by providing basic services. One implication of this is a rural bias in the impact of democracy on basic health and education outcomes. Using individual-level data from 27 African countries, I investigate the theoretical claim that competitive elections create incentives for African governments to implement prorural policies in order to satisfy the rural majority. The results demonstrate that democratic elections significantly increase access to primary education and reduce infant mortality rates, but only for children in rural areas. As the argument expects, these effects are conditional on the level of urbanization.

$\mathrm{H}$ ow do African governments respond to democratic electoral competition? The common perception is that they have pursued mixed strategies, combining various types of electoral fraud, clientelism, and ethnic mobilization. But there is an alternative possibility that has received far less attention: that African governments have sought to win electoral support through the provision of basic services. Although fraud, clientelism, and ethnic politics are certainly widespread across Africa, I argue that this alternative is more than just a possibility; democratic elections in Africa induce governments to compete for votes by providing basic services. This does not mean that democratic rulers are benevolent welfare maximizers, nor does it mean that any effect of democracy on changes to the provision of basic services will be experienced equally across society, since democratic rulers select policies to court the votes of an electoral majority. But one thing it does mean is that across Africa the effect of democracy on changes to basic health and education outcomes has been larger in rural areas.

This conclusion follows a recognition that competitive elections create incentives for governments to implement policies that increase the provision of basic services, in order to win the support of an electoral majority. ${ }^{1}$ While urban bias under autocracies rendered rural areas relatively deprived, the electoral incentives introduced by democracy mean that rural voters can no longer be ignored. Since in most African countries a majority of the population lives in rural areas, African governments that are subject to meaningful electoral constraints have incentives to pursue policies that benefit the interests of this rural majority. This does not mean that under democracy rural areas necessarily receive more public goods than urban areas, but it does imply that rural areas should benefit relatively more from democracy in terms of the positive changes resulting from increased public goods provision. It also implies that the extent of any differential effect of democracy should be conditional on and decreasing in the level of urbanization. As urbanization increases and the electoral importance of the countryside recedes, so too should the imperative to satisfy previously disadvantaged rural voters. As such, the argument expects heterogeneity in the relative effects of democracy for urban and rural areas, because of variation in urbanization at the national level.

The empirical task is therefore to investigate whether the introduction of democratic elections across Africa has led to differential effects on basic service provision across urban and rural areas and whether the extent of this is conditional on urbanization. Using individual-level data across 27 African countries from the Demographic and Health Survey (DHS)

Robin Harding (robin.harding@politics.ox.ac.uk) is an associate professor at the University of Oxford, Manor Road, Oxford, OX1 3UQ, United Kingdom.

Data and supporting materials necessary to reproduce the numerical results in the article are available in the JOP Dataverse (https://dataverse.harvard.edu /dataverse/jop). An online appendix with supplementary material is available at https://doi.org/10.1086/705745.

1. Recent evidence demonstrates that voters in Africa can be responsive to the provision of public or collective goods and services (Harding 2015; Weghorst and Lindberg 2013).

The Journal of Politics, volume 82, number 1. Published online November 14, 2019. https://doi.org/10.1086/705745

(C) 2019 by the Southern Political Science Association. All rights reserved. 0022-3816/2020/8201-0017\$10.00 
series, I focus on the impact of democracy on the most basic health and education outcomes: primary education and infant mortality rates. Doing so demonstrates a substantial rural bias in the positive effects of democratic elections. I also show that the extent of this rural bias is conditional on and decreasing in the level of urbanization, as the theory suggests. Additional analyses address alternative explanations, allaying concerns that the results may be driven by pretrends or by ethnic favoritism in the distribution of resources.

Democracy can be defined and measured in a multitude of ways. Following Cheibub and Przeworski (1999), I focus primarily on a measure that takes democracy to be given by multiparty elections that have led to the replacement in power of the chief executive. Although potentially contentious, the replacement criterion has the virtue of restricting the set of democracies to cases for which we can be certain that multiparty elections represent a meaningful constraint on the executive. This virtue makes the measure theoretically appropriate, since it is possible that elections which do not represent binding constraints may be insufficient to generate incentives for incumbents to design policies with the purpose of constructing an electoral majority. I also investigate the effects of a purely procedural measure that discards the replacement criterion, taking as democracies any countries where the chief executive was elected in multiparty elections. In line with previous findings, I show that multiparty elections have a positive effect on basic health and education outcomes, irrespective of executive replacement. But the evidence for rural bias in these effects is less compelling, suggesting that only elections that represent a meaningful constraint on the executive are sufficient to induce the theorized electoral incentives.

This research builds on work by Bates (1981) and Bates and Block (2013), who considered the conditions under which agricultural policies might be designed to prioritize urban or rural interests in Africa and provided evidence that competitive elections have led to policy reforms that enhance agricultural productivity. It is also closely related to work by Stasavage (2005), who demonstrated that the introduction of elections in Africa led to an increase in government spending on primary but not secondary education, due to stronger rural preferences for primary education. I build on this work by broadening the focus to basic service provision more generally and by looking at the impact of competitive elections on individual-level health and education outcomes, rather than inputs at the national level, to disaggregate the effects between urban and rural residents.

This research contributes to an extensive literature that addresses the impact of democracy on the provision of public goods and services. As well as providing strong additional evidence that democracy has a positive effect on education and health outcomes in Africa, it disaggregates this effect, demonstrating that democracy has a significantly larger impact on changes to basic service provision for rural residents than for urbanites. These findings suggest that to properly understand the effects of democracy, it is important to consider who should benefit. In doing so, this article complements the research by Harding and Stasavage (2014), who consider the types of policy outcomes that should be affected by democracy. This article also contributes to research on electoral politics in Africa more generally, much of which has focused on the prevalence of electoral fraud, ethnic competition, and clientelism. While these practices are certainly widespread, the results presented herein suggest that African governments also seek to construct electoral majorities through basic service provision.

\section{WHO SHOULD BENEFIT FROM DEMOCRACY IN AFRICA?}

There is a growing consensus that democracy can have a positive effect on basic services, with various empirical studies having demonstrated the existence of broad relationships between measures of democracy and indicators of public goods outcomes at the national level. ${ }^{2}$ In addition, some more recent work has sought to disaggregate the effects of democracy across different groups (e.g., Brown and Mobarak 2009; Burgess et al. 2015; Kroth, Larcinese, and Wehner 2016; Min 2015). These disaggregated studies highlight that it is useful to think about who benefits - are the effects of democracy uniform across all individuals, or do some benefit more than others? The argument motivating the empirical analysis is that the positive effects of any increase in basic service provision resulting from democracy should be felt more strongly for rural residents, because the incentives created by competitive elections mean that African governments cannot ignore the interests of the rural majority, as had previously been the case.

This argument takes its lead from work on the relationship between regime type and public goods that gives primacy to the role of accountability, such as that by Bueno de Mesquita et al. (2001) and Lake and Baum (2001). From this perspective, democracy increases public goods provision because competitive elections render politicians accountable to the mass electorate. To stay in power, governments need the support of a majority of voters. One way to construct an electoral majority is by providing private goods through patronage networks. Given the large numbers of voters involved in popular elections, however, a potentially cheaper and more feasible alternative is to

2. Studies have investigated the relationship between democracy and health care and education spending and outcomes such as infant mortality rates, literacy levels, and electrification. Examples include Besley and Kudamatsu (2006), Ross (2006), and Stasavage (2005). 
implement policies that increase the provision of public goods and services. As a result, we should see a positive relationship between democratization and basic service provision.

This positive relationship should lead to improvements in basic health and education outcomes, as has been evidenced in Africa by Harding and Stasavage (2014) and Kudamatsu (2012). One question that follows is whether these changes should be felt by all citizens equally or whether some should benefit relatively more from democracy in terms of any increase in public goods provision. An answer is suggested by the urban bias literature, which argued that authoritarian regimes in developing countries have incentives to favor urban over rural interests because the primary threat to this type of regime comes from revolutions or coups, which tend to germinate in urban areas where coordinating collective action is easier (Bates 1981). However, these incentives should change with the onset of democracy, because under a democratic regime the primary threat to government survival comes instead from electoral defeat. ${ }^{3}$ Consequently, since survival depends on securing an electoral majority, where a majority of the population lives in rural areas (as is the case across most of sub-Saharan Africa, for the time being at least), under democracy it is no longer possible to ignore rural voters. ${ }^{4}$

If elections in countries with rural majorities create incentives for governments to cater to rural interests that had previously been ignored, the introduction of democracy in such contexts should result in the extension of, and improvements to, basic service provision for rural areas. That is not to say that under democracy voters in rural areas necessarily receive more public goods than urbanites, and it may be the case that urban areas continue to experience higher levels of public goods provision following transitions to democracy. But what it does mean is that because of the urban bias documented for autocracies, rural areas should benefit relatively more from democracy in terms of the positive changes resulting from increased public goods provision. ${ }^{5}$

3. Urbanites do not lack power under democracy since they can protest and strike, for example. But democracy increases the relative power of rural residents compared to urbanites.

4. The literature on redistributive politics has focused on whether benefits should accrue primarily to swing voters or core supporters. Stokes et al. (2013) explain the targeting of core voters with clientelist distribution in developing democracies by highlighting the role of brokers. The focus here is on nonclientelist forms of distributive politics.

5. It also does not necessarily imply that the urban-rural cleavage entirely prevails over other possible cleavages, such as ethnicity, because rural areas could still benefit relatively more from democracy than urban areas even if governments are pursuing policies of ethnic favoritism. However, both Burgess et al. (2015) and Franck and Rainer (2012) provide evidence that ethnic favoritism recedes under democracy. In the data the correlation between rural location and the measure of leader coethnicity (as described
Although by definition public goods are nonexcludable and nonrivalrous, it is possible for the benefits of basic service provision to accrue differentially across individuals because of both programmatic distribution and what Stokes et al. (2013) label "nonconditional partisan bias." Governments everywhere implement forms of distributive politics that exhibit nonconditional partisan bias, more commonly referred to as pork barrel politics. Either these forms of distribution lack formalized and public criteria, or these criteria do not actually shape distribution (or both). As such, the actual determinants of distribution are often partisan, in that they are designed to generate goodwill for a particular political candidate or party (Stokes et al. 2013, 12). That they are nonconditional is important because the receipt of benefits does not depend on individual support; benefits are intended to sway voters, not buy them. ${ }^{6}$ It is fairly easy to imagine how the targeted distribution of local public goods could lead to rural areas benefiting more from any increase in the provision of basic services resulting from democracy, for example, through building more primary schools and health clinics in rural areas.

Programmatic forms of distribution are guided by criteria that are formalized and public and that actually shape the distribution of resources (Stokes et al. 2013, 7). However, although programmatic policies are often ostensibly universal, their benefits are frequently felt more keenly by some voters than others, because of variations in need or preferences. ${ }^{7}$ Knowing this, governments can also use programmatic policy instruments to effectively target certain groups of voters. Both programmatic and targeted forms of distribution therefore provide policy instruments that can be used to differentially benefit rural areas. Again, though, that does not mean that urbanites under democracy are ignored; increasing urbanization, greater economies

below) is -0.0238 . That between rural location and a measure of household wealth is -0.5373 . While this measure of wealth is the only one available in the DHS data, it is problematic because it is calculated using factors such as access to services. This measure has been widely criticized for a variety of reasons, including the fact that it lacks comparability across urban and rural areas (Rutstein 2008).

6. This sets pork barrel politics apart from clientelism, which here refers to the conditional distribution of private benefits to either party members (patronage) or voters (vote buying or turnout buying; Stokes et al. 2013).

7. The Ghanaian National Health Insurance Scheme (NHIS) provides an example of a programmatic policy whose benefits accrue differentially in this way. The NHIS offers programmatic benefits to all citizens, but the nature of the resources provided means that rural residents are likely to benefit more than urbanites because they are more likely to lack the financial resources to purchase essential health services in the absence of the NHIS. The widespread abolition of primary school fees in Africa highlighted by Harding and Stasavage (2014) represents another example of how programmatic policies can have differential effects across types of citizens, as poorer (and rural) citizens are more likely to experience school fees as a binding constraint that prevents take-up of access to primary education. 
of scale, and the relative difficulty of enforcing clientelistic exchanges in urban areas (Nathan 2016) could actually make the provision of public goods to urban voters even more electorally attractive. But if service provision was urban biased under autocracy, and the introduction of electoral incentives means that rural voters can no longer be ignored, it follows that rural areas should benefit relatively more from democracy in terms of the increase in such provision.

If electoral competition creates incentives to satisfy rural voters, the impact of these incentives should be conditional on urbanization. In countries with very low levels of urbanization, the presence of extremely large rural majorities increases the imperative to court rural voters. As urbanization increases and the electoral importance of the countryside recedes, so too should this imperative. In cases where rural voters are in the minority, the need for governments to satisfy them with prorural policies designed to offset previous urban bias should be reduced. As such, we should see the greatest rural bias in the impact of democracy on education and health outcomes in countries that are predominantly rural, and the extent of this bias should decrease with urbanization. ${ }^{8}$ The argument outlined above has three observable implications: (1) democracy in Africa should lead to positive changes in basic education and health outcomes; (2) the extent of these positive changes should be greater in rural areas; (3) the extent of this rural bias should be decreasing in the level of urbanization.

While the empirical focus herein is on robustly evaluating the implications of this argument, it is important to acknowledge that the focus is on outcomes rather than mechanisms. Although it is beyond the scope of this study, to fully understand the relationship between democracy and basic health and education outcomes requires consideration of the precise policy mechanisms through which democracy affects the provision of basic services. For example, as Harding and Stasavage (2014) have shown, the effect of democracy is likely to work through specific policies such as the abolition of user fees. Future work should investigate these policy mechanisms further and in more detail.

\section{THE EFFECT OF DEMOCRACY ON EDUCATION AND HEALTH}

This section considers how to estimate the effect of democracy on education and health outcomes. First it addresses questions

8. An alternative explanation could be that policies designed to improve health and education outcomes equally for all just happen to have greater effects for rural residents, leading to a convergence in health and education outcomes across urban and rural areas. Evidence that the extent of rural bias is conditional on urbanization counters this alternative explanation, which does not obviously imply such a conditional effect. of how to measure the key dependent and independent variables, and then it discusses the estimation method that is employed.

\section{Measuring democracy}

Scholars investigating the impact of democracy on basic service provision have adopted various approaches to defining and measuring democracy. One approach is to focus solely on formal institutions, taking as democratic all countries where the chief executive was elected in multiparty competition. This purely procedural approach has the great benefit of providing "an objective ex ante measure of formal institutions, as opposed to a subjective measure (such as Polity or Freedom House) that may be influenced by ex post outcomes" (Harding and Stasavage 2014, 234). Moreover, in justifying this minimalist approach for examining the impact of democracy on basic service provision, Harding and Stasavage argue that even an unlevel electoral playing field can generate incentives for incumbents to choose policies in order to maximize vote share.

An alternative approach is to require certain conditions that limit the set of democracies to cases in which the playing field is more level. This is exemplified by Kudamatsu (2012), who follows Cheibub and Przeworski (1999) in requiring not only that the chief executive is elected in multiparty competition but also that elections have led to the replacement in power of the chief executive. The virtue of this additional criterion is to err on the side of prudence; as Cheibub and Przeworski (1999) note, the problem with classifying regimes is that some cases meet the formal institutional criteria for democracy yet the incumbent always wins. In these cases it remains unclear whether the incumbents would have held elections if they were not certain of victory and whether they would have yielded power if they had actually lost. Therefore, the prudent approach is to opt for type II errors, classifying these cases as not democratic when in fact they might have been. This is a particularly pertinent issue in Africa, where in many cases the rapid introduction of multiparty elections in the 1990s did not immediately lead to the replacement of authoritarian incumbents.

In essence, the replacement criterion represents an objective (if somewhat blunt) indicator of democratic quality, the addition of which restricts the set of democracies to cases in which we can be certain that multiparty elections impose a meaningful constraint on the executive. ${ }^{9}$ As Harding and Stasavage (2014) show, this higher democratic bar is not necessary

9. An alternative would be to use a more subjective measure such as Polity, but doing so forfeits the benefit of objectivity. Results from estimates using Polity are presented in table B.1 (tables A.1-A.4, B.1-B.19 are available online). 
to induce policy change; multiparty elections are sufficient to encourage the implementation of policies such as free primary schooling, for example, which has led to a significant increase in primary school enrollment across Africa. What is not yet clear, however, is whether an unlevel electoral playing field is sufficient to generate incentives for incumbents to pursue more costly policy changes or more demanding electoral strategies.

Even with an uneven electoral playing field, fairly costless policies that maximize vote share - such as abolishing school fees - may be desirable to the extent that they offset the costs of vote rigging. But elections that do not represent binding constraints may be insufficient to generate incentives for incumbents to design and implement policies with the purpose of constructing an electoral majority. Especially where they involve targeted resource provision, such electoral strategies may be more costly than rigging elections. Instead then, it is possible that only incumbents who are prepared to lose, and who are unwilling to rig or coerce their way to an electoral majority, will face such incentives. If this is the case, then the minimalist approach may not uncover the hypothesized rural bias, because it would include as democratic cases in which incumbents do not face the requisite incentives.

I proceed by using both approaches to measuring democracy. I focus primarily on a measure that includes the replacement criterion because it is potentially more theoretically appropriate. To this end I construct a "democracy" measure using the coding provided by Kudamatsu (2012), updated to cover the additional years in my sample. ${ }^{10}$ In addition, I follow Harding and Stasavage (2014) in constructing a "multiparty" measure using data from the Database of Political Institutions (Beck et al.2001) to determine whether a country's chief executive was elected in multiparty competition. ${ }^{11}$

\section{Measuring education and health outcomes}

National-level development indicators highlight that levels of basic service provision in Africa remain the lowest in the

10. Following Kudamatsu $(2012,1298)$, "democracy is defined as a political system where (1) the chief executive of the national government has been elected in multiparty elections with universal suffrage, without subsequently banning opposition parties; and (2) a new chief executive has assumed office by winning multiparty elections."

11. In line with Harding and Stasavage (2014), I code a country as having multiparty competition for any year in which the chief executive was in place as a result of multiparty electoral competition in which more than one party won votes, using data from the Database of Political Institutions (Beck et al. 2001). The database's Executive Index of Electoral Competitiveness codes the elected status of the executive for each country-year on a seven-point scale: 1 , no executive; 2 , unelected executive; 3 , elected, one candidate; 4 , one party, multiple candidates; 5 , multiple parties are legal but only one party won votes; 6 , multiple parties won votes, but the largest party received more than $75 \%$ of the votes; 7 , largest party got less than $75 \%$. A country is coded as having multiparty competition for any year it is coded 6 or 7 on this scale. world. In 2012, infant mortality rates in sub-Saharan Africa were almost twice as high as the global average, and net primary school enrollment was 13 percentage points lower. ${ }^{12}$ Within Africa, rural residents fare much worse than urbanites. Since 1980, children in rural areas have been $15 \%$ less likely to receive any schooling than those living in urban locations, and infant mortality rates have been 20 percentage points higher.

Measuring the impact of democracy on basic service provision requires data on education and health outcomes across countries, before and after the introduction of competitive elections, that can be disaggregated below the national level to differentiate the effects for rural as opposed to urban residents. Official education statistics collected by UNESCO provide time series data on various education inputs and outcomes, but these national-level data do not allow for disaggregating the effects across urban and rural areas. The same is true for country-level data on infant mortality provided by UNICEF and the World Bank. As an alternative, I construct time series measures of infant mortality rates and primary school attendance using individual-level survey data from the DHS series.

The DHS provide high-quality individual-level data on a variety of development indicators, including education attainment and child health, for over 90 countries around the world. I use data from the most recent surveys at the time of writing, from 27 African countries. ${ }^{13}$ The DHS are carried out at the household level, and the data contain information on years of schooling completed for all individuals in each household. In addition, a survey of women collects birth histories for all mothers surveyed, providing information on infant mortality. ${ }^{14}$

For the infant mortality estimates, I have a total sample of 879,856 children, born to 231,784 mothers, every year from 1980 through to the survey date. For each child I construct the variable Infant Death, coded 1 if the child died before her first birthday and 0 otherwise. To measure the impact

12. Data are from the World Bank's World Development Indicators (http://datatopics.worldbank.org/world-development-indicators/).

13. This includes all of the countries analyzed by Kudamatsu (2012) apart from Mauritania, for which data access is restricted. A full list of the surveys used in the analysis is in the appendix (available online).

14. Educated people tend to live longer (Cutler and Lleras-Muney 2006). Consequently, including all individuals born since independence will introduce bias because many more individuals who were of primary school age before the introduction of democracy but who did not go to school are less likely to be observable than those of the same age who did go to school. Therefore, to limit bias resulting from the effects of education on life expectancy, and in line with Harding and Stasavage (2014), I restrict all of the analyses to children born since 1980 . For the infant mortality estimates, doing so has no substantive effect on the results, as expected. 
of democracy on infant mortality, I code the variables Multiparty and Democracy as 1 if the child was born in a country that was democratic by the relevant measure throughout the year in which she was born and 0 otherwise..$^{15}$ For the education estimates, I have a total sample of 578,695 individuals, from 267,383 households, born every year from 1980 through to the survey date minus the statutory primary school completion age. For each individual, I construct the dummy variable Any Schooling, coded 1 if an individual has ever attended primary school and 0 otherwise.

To measure the impact of democracy on primary schooling I code the variables Multiparty and Democracy to capture the proportion of an individual's primary school age years spent in a context of democracy, again by the relevant measure. ${ }^{16}$ These variables take a value of 1 for all cases in which an individual reached the official age of school entry subsequent to the introduction of democracy. If an individual reached the normal school leaving age before competitive elections being introduced, the variables take a value of 0 . Finally, in cases in which an individual reached the normal age of school entry before competitive elections were introduced, but elections were subsequently introduced before the individual reached normal school leaving age, the variables take a value between 0 and 1 equal to the proportion of the school age years spent under democracy.

\section{Estimation method}

I use these data to evaluate the impact of democracy on infant mortality rates and access to primary education by estimating the following equation with a linear probability model:

$$
Y_{\text {imct }}=\mu_{m}+\delta_{t}+\beta \text { Democracy }_{\text {imct }}+\gamma X_{\text {imct }}+\theta_{c t}+\varepsilon_{\text {imct }} .
$$

For the dependent variable, $Y_{\text {imct }}$ equals 1 if individual $i$ born to mother $m$ (or living in household $m$ ) in country $c$, born in year $t$, either died before reaching her first birthday or ever attended primary school, depending on the outcome under investigation. Of principal interest is the Democracy (or Multiparty) variable, which captures either whether the child was born in a democracy or the proportion of an individual's primary school age years spent under democracy. Year-of-birth fixed effects are represented by $\delta_{t}$, and $\theta_{c t}$ represents a countryspecific linear time trend, which controls for any country-level changes in education that are unrelated to electoral competition. For all estimates, the matrix $X_{\text {imct }}$ contains dummy var-

15. This approach follows that of Kudamatsu (2012).

16. Official primary school ages vary by country and are available from UNESCO (http://data.uis.unesco.org). iables for birth order and gender. For the estimates of infant mortality, $X_{\text {imct }}$ also contains a dummy variable for multiple births (i.e., twins, triplets, or quadruplets). For the estimates of primary education, $X_{i m c t}$ also contains dummy variables to control for relationship to household head. Since Democracy does not vary across individuals born in the same country in a given year, standard errors are clustered by country-yearof-birth.

For the estimates of infant mortality, $\mu_{m}$ represents mother fixed effects, and when the outcome of interest is access to primary education, $\mu_{m}$ represents household fixed effects. Including household fixed effects is useful for the education analysis because it means estimating the effect of democracy only for households in which there were children of primary school age both before and after democratization. This controls for any potentially confounding household-level characteristics that may vary systematically over time within a country and that might affect both the chances of democratization and access to primary education. ${ }^{17}$ Including mother fixed effects for the estimates of infant mortality brings similar benefits; doing so exploits within-mother variation in infant survival, providing confidence that any estimated effect of democracy is robust to the possibility that broader demographic changes might affect both regime type and infant survival rates. ${ }^{18}$ If democratic elections in Africa reduce infant mortality rates, the coefficient on the Democracy variable should be negative; if democratic elections increase primary school attendance, the coefficient should be positive.

To evaluate the theoretical expectation of a rural bias in the impact of democracy on basic service provision requires estimating these effects separately for urban and rural areas. The simplest way to achieve this is to split the sample using information about whether respondents live in urban or rural locations. This information is coded into the DHS data at the household level using national census files. Therefore, as well as estimating equation (1) for the full sample, I estimate all of the models separately for urban and rural respondents. An alternative approach is to include an interaction term between the Democracy variable and the rural location dummy

17. This follows the estimation strategy pursued by Harding and Stasavage (2014). Another benefit of this strategy is to rule out the possibility of reverse causality; previous work has indicated that education leads to democracy (e.g., Glaeser, Ponzetto, and Shleifer 2007; Larreguy and Marshall 2017), but the fixed effects strategy employed here deals with this identification problem because the individuals under examination are too young to be driving the democratic changes.

18. This follows the strategy pursued by Kudamatsu (2012). The models estimated herein differ from Kudamatsu's preferred specification, which includes dummy variables for mothers' birth cohorts. Including these has no substantive effect on my results but is incredibly computationally intensive, so I omit them from the analysis for ease of replication. 
in the estimates using the full sample. Doing so yields very similar results, which are presented in table B.15. For ease of interpretation I split the sample between urban and rural residents, but it is worth highlighting that the estimates using the interaction term demonstrate that the urban-rural differences in the effect of democracy are statistically significant at standard levels.

The argument also predicts that the extent of rural bias should be conditional on the national level of urbanization. I evaluate this implication by estimating the following equation:

$$
\begin{aligned}
Y_{\text {imct }}= & \mu_{m}+\delta_{t}+\beta 1 \text { Democracy }_{\text {imct }}+\beta 2 \text { Urbanization }_{c t} \\
& +\beta 3\left(\text { Democracy }_{\text {imct }} \times \text { Urbanization }_{c t}\right) \\
& +\gamma X_{\text {imct }}+\theta_{c t}+\varepsilon_{\text {imct }},
\end{aligned}
$$

where $\beta 2$ represents the effect of the level of urbanization in country $c$ in year $t$, with $t$ being equal to the child's year of birth for the infant mortality estimates and the year that the child reaches primary school age for the education estimates. Urbanization data are taken from the World Bank's database of
World Development Indicators. Since the expectation is that the extent of rural bias in the effect of democracy should be conditional on the level of urbanization, the key parameter of interest is $\beta 3$, which represents the effect of an interaction between the Democracy and Urbanization variables. If the theoretical argument is correct, this term should be positive and significant in the estimates of infant mortality for rural residents and significantly negative in the education estimates for rural residents. There is no reason to expect it to be significant in the estimates for urban residents.

\section{RESULTS}

Table 1 contains results from estimates of equation (1). The outcome of interest in panel $\mathrm{A}$ is whether a child died before her first birthday, and in panel B it is whether a child ever attended primary school.

\section{Average effects of democracy}

The results from models 1 and 7 show the average effect of

\begin{tabular}{|c|c|c|c|c|c|c|}
\hline & \multicolumn{2}{|c|}{ All } & \multicolumn{2}{|c|}{ Urban } & \multicolumn{2}{|c|}{ Rural } \\
\hline & (1) & (2) & (3) & (4) & (5) & (6) \\
\hline \multicolumn{7}{|l|}{ A. $\mathrm{DV}=$ infant death: } \\
\hline Democracy & $\begin{array}{r}-.0032^{\star} \\
(.0017)\end{array}$ & & $\begin{array}{c}-.0016 \\
(.0023)\end{array}$ & & $\begin{array}{c}-.0041^{\star *} \\
(.0021)\end{array}$ & \\
\hline Multiparty & & $\begin{array}{c}-.0068^{* * *} \\
(.0015)\end{array}$ & & $\begin{array}{c}-.0023 \\
(.0022)\end{array}$ & & $\begin{array}{c}-.0083^{* * *} \\
(.0017)\end{array}$ \\
\hline Number of mothers & \multicolumn{2}{|c|}{231,784} & \multirow{2}{*}{\multicolumn{2}{|c|}{$\begin{array}{r}75,408 \\
240,690\end{array}$}} & \multicolumn{2}{|c|}{156,376} \\
\hline \multirow[t]{2}{*}{ Observations } & \multicolumn{2}{|c|}{879,856} & & & \multicolumn{2}{|c|}{639,166} \\
\hline & (7) & (8) & (9) & (10) & (11) & (12) \\
\hline \multicolumn{7}{|l|}{ B. DV = any schooling: } \\
\hline Democracy & $\begin{array}{l}.0133^{\star *} \\
(.0058)\end{array}$ & & $\begin{array}{c}.0036 \\
(.0067)\end{array}$ & & $\begin{array}{l}.0205^{\star * *} \\
(.0074)\end{array}$ & \\
\hline Multiparty & & $\begin{array}{l}.0157^{\star \star \star} \\
(.0058)\end{array}$ & & $\begin{array}{l}.0203^{\star * *} \\
(.0054)\end{array}$ & & $\begin{array}{l}.0121^{\star} \\
(.0072)\end{array}$ \\
\hline Number of households & & & & & & \\
\hline Observations & & & & & & \\
\hline
\end{tabular}
democracy on infant mortality and access to primary education,

Table 1. Effects of Democracy on Basic Service Provision

Note. Estimates from linear probability models of the effect of democracy on infant mortality rates (A) and access to primary education (B). All estimates include gender and birth order dummies, year-of-birth fixed effects, country-specific linear time trends, and either mother fixed effects (A) or household fixed effects (B). Estimates of infant mortality also include a dummy for multiple births. Estimates of primary education also include dummies for relationship to household head. Standard errors in parentheses, clustered by country-year-of-birth. Number of countries $=27 . \mathrm{DV}=$ dependent variable.

$* p<.1$.

${ }^{* *} p<.05$.

${ }^{* * *} p<.01$. 
respectively, for all individuals across the 27 countries. From these it is clear that democratization has led to improvements in basic education and health outcomes across Africa. For infant mortality, the implied effect of a child being born into a democracy as opposed to a nondemocratic regime is a reduction in the probability of her dying before her first birthday of just under one-third of a percentage point. More concretely, this implies that the introduction of democracy leads to 3.2 fewer infants dying before reaching one year of age, for every 1,000 live births. For access to primary education, the implied average effect of a child spending all her primary school age years in a democracy as opposed to a nondemocracy is an increase in the probability of her ever attending school of 1.3 percentage points. For both outcomes these average effects are statistically significant at or close to the .05 level. ${ }^{19}$

When the Multiparty variable is used instead (models 2 and 8), the average effect on access to primary education is very similar. For infant mortality the implied effect is more than twice the size, suggesting that major gains in infant health may have followed the introduction of multiparty elections, irrespective of whether these elections led to incumbent turnover. These results provide strong evidence that, on average, the introduction of democratic elections in Africa significantly and substantially reduces infant mortality rates and increases access to primary schooling. Moreover, they suggest that even where the playing field is uneven, multiparty electoral competition generates incentives for incumbents to pursue vote-maximizing policies that improve basic health and education outcomes.

The average effects therefore support the theoretical claim that democracy generates electoral incentives for governments to improve basic service provision. But electoral success does not require winning all the votes, only a majority. And since most African countries have rural majorities, we should expect the benefits of democracy to be felt primarily by rural residents. The next step is therefore to investigate whether the effects of democracy on changes to basic education and health outcomes have been felt more strongly by rural residents.

\section{Evidence of rural bias}

The results from models 3 and 5 show the effect of democracy on infant mortality for urban and rural residents, respectively. Those from models 9 and 11 do the same for access to primary education. These results demonstrate a clear rural bias in the impact of democracy on changes to basic education and health outcomes. For infant mortality, democracy has no significant effect on the probability of children in urban areas reaching

19. For the infant mortality estimate $p=.064$, and for the education estimate $p=.021$. age 1. Instead, the significant average effect is driven by the impact of democracy on infant mortality in rural areas. When equation (1) is estimated for the rural subsample, the effect is greater than the estimated average effect and is significant at the .05 level. These results imply that for children in rural areas, being born into a democracy reduces the probability of dying before age 1 by almost half a percentage point. For every 1,000 live births in rural areas, the implied effect of democracy is that 4.1 more infants celebrate their first birthdays.

The story is similar for access to primary education. When equation ( 1 ) is estimated only for urbanites, the effect is little more than a quarter of the average estimated effect and is not statistically significant. In contrast, for the rural subsample the effect is significant at the .01 level and is more than $50 \%$ larger than the average estimated effect. For a child in a rural area, the implied effect of spending all her primary school age years in a democracy is to increase the probability of her going to school by 2 percentage points. For both education and health outcomes, these results provide clear evidence of a rural bias in the improvements resulting from democracy; democratization across Africa has led to positive changes in basic health and education outcomes for rural residents but has had no such effect in urban areas. Pooling the data across urban and rural residents and including an interaction term between the Democracy variable and a dummy for rural location yields very similar results and demonstrates that the urban-rural differences in the effects of democracy on access to primary education and infant mortality rates are statistically significant at the .05 level (results included in table B.15).

When the Multiparty variable is used a similar pattern emerges, although for the education estimates the evidence for rural bias is slightly less compelling. For infant mortality (models 4 and 6) the introduction of multiparty elections has a substantially smaller effect for urbanites than for rural residents and is only statistically significant for the latter. For education the estimated effect is larger for the urban subsample. Again, though, pooling the data and including an interaction term between the Multiparty variable and a dummy for rural location demonstrates that the effects of democracy on access to primary education and infant mortality rates are significantly larger for rural residents than for urbanites.

\section{Are the effects of democracy conditional on urbanization?}

The third stage in the empirical strategy is to investigate whether the rural bias in the impact of democracy is conditional on urbanization. If governments implement prorural policies in order to court the votes of the rural majority, it follows that the extent to which this strategy is pursued 
should depend on the size of that rural majority. To evaluate this, I interact the Democracy and Multiparty variables with a measure of urbanization at the national level. The results are presented in table 2. Panel A shows results from estimates of equation (2) when the outcome of interest is infant mortality.

When the entire sample is used, the results from model 1 show a significant interaction effect between democracy and urbanization, in the expected direction. While democracy reduces infant mortality rates, this effect decreases as the level of urbanization increases. Again, though, of greater interest is the difference in the conditional effect of democracy across urban and rural residents. As before, this can be investigated by splitting the sample and reestimating equation (2) separately for urban and rural residents. The results from models 3 and 5 show that there is no significant effect of democracy for urban residents, nor is there a significant interaction between democracy and urbanization. Instead, the average conditional effects are driven by the conditional effects of democracy on infant mortality for rural residents.

Table 2. Conditional Effects of Democracy on Basic Service Provision

\begin{tabular}{|c|c|c|c|c|c|c|}
\hline & \multicolumn{2}{|c|}{ All } & \multicolumn{2}{|c|}{ Urban } & \multicolumn{2}{|c|}{ Rural } \\
\hline & (1) & $(2)$ & (3) & (4) & (5) & (6) \\
\hline \multicolumn{7}{|l|}{ A. $\mathrm{DV}=$ infant death: } \\
\hline Democracy & $\begin{array}{c}-.0128^{\star *} \\
(.0054)\end{array}$ & & $\begin{array}{r}-.0069 \\
(.0074)\end{array}$ & & $\begin{array}{c}-.0143^{\star *} \\
(.0061)\end{array}$ & \\
\hline Urbanization & $\begin{array}{c}-.0023^{* * *} \\
(.0006)\end{array}$ & $\begin{array}{c}-.0019^{* * *} \\
(.0006)\end{array}$ & $\begin{array}{c}-.0019^{* *} \\
(.0008)\end{array}$ & $\begin{array}{c}-.0018^{\star *} \\
(.0008)\end{array}$ & $\begin{array}{c}-.0025^{\star * \star} \\
(.0008)\end{array}$ & $\begin{array}{c}-.0020^{* *} \\
(.0008)\end{array}$ \\
\hline Democracy $\times$ urbanization & $\begin{array}{l}.0003^{\star *} \\
(.0002)\end{array}$ & & $\begin{array}{c}.0002 \\
(.0002)\end{array}$ & & $\begin{array}{l}.0004^{\star *} \\
(.0002)\end{array}$ & \\
\hline Multiparty & & $\begin{array}{c}-.0068^{* *} \\
(.0033)\end{array}$ & & $\begin{array}{c}-.0044 \\
(.0044)\end{array}$ & & $\begin{array}{r}-.0070^{*} \\
(.0041)\end{array}$ \\
\hline Multiparty $\times$ urbanization & & $\begin{array}{c}.0000 \\
(.0001)\end{array}$ & & $\begin{array}{c}.0001 \\
(.0001)\end{array}$ & & $\begin{array}{r}-.0000 \\
(.0001)\end{array}$ \\
\hline Number of mothers & \multicolumn{2}{|c|}{231,784} & \multicolumn{2}{|c|}{75,408} & \multicolumn{2}{|c|}{156,376} \\
\hline \multirow[t]{2}{*}{ Observations } & \multicolumn{2}{|c|}{879,856} & \multicolumn{2}{|c|}{240,690} & \multicolumn{2}{|c|}{639,166} \\
\hline & (7) & (8) & (9) & (10) & (11) & (12) \\
\hline \multicolumn{7}{|l|}{ B. DV = any schooling: } \\
\hline Democracy & $\begin{array}{l}.0428^{\star *} \\
(.0171)\end{array}$ & & $\begin{array}{c}.0231 \\
(.0201)\end{array}$ & & $\begin{array}{l}.0489^{* *} \\
(.0206)\end{array}$ & \\
\hline Urbanization & $\begin{array}{l}.0110^{* * *} \\
(.0020)\end{array}$ & $\begin{array}{l}.0119^{* * *} \\
(.0020)\end{array}$ & $\begin{array}{l}.0048^{* * *} \\
(.0017)\end{array}$ & $\begin{array}{l}.0048^{* * *} \\
(.0017)\end{array}$ & $\begin{array}{l}.0153^{\star * *} \\
(.0029)\end{array}$ & $\begin{array}{l}.0169^{* * *} \\
(.0029)\end{array}$ \\
\hline Democracy $\times$ urbanization & $\begin{array}{r}-.0012^{*} \\
(.0006)\end{array}$ & & $\begin{array}{r}-.0007 \\
(.0007)\end{array}$ & & $\begin{array}{r}-.0013^{*} \\
(.0008)\end{array}$ & \\
\hline Multiparty & & $\begin{array}{l}.0468^{\star * \star} \\
(.0109)\end{array}$ & & $\begin{array}{l}.0421^{\star * *} \\
(.0104)\end{array}$ & & $\begin{array}{l}.0562^{\star * *} \\
(.0139)\end{array}$ \\
\hline Multiparty $\times$ urbanization & & $\begin{array}{c}-.0014^{* * *} \\
(.0003)\end{array}$ & & $\begin{array}{c}-.0008^{\star * *} \\
(.0003)\end{array}$ & & $\begin{array}{c}-.0021^{* * *} \\
(.0005)\end{array}$ \\
\hline Number of households & \multicolumn{2}{|c|}{267,383} & \multicolumn{2}{|c|}{91,826} & \multicolumn{2}{|c|}{175,557} \\
\hline Observations & \multicolumn{2}{|c|}{578,695} & \multicolumn{2}{|c|}{206,204} & \multicolumn{2}{|c|}{372,491} \\
\hline
\end{tabular}

Note. Estimates from linear probability models of the effect of democracy on infant mortality rates (A) and access to primary education (B). All estimates include gender and birth order dummies, year-of-birth fixed effects, country-specific linear time trends, and either mother fixed effects (A) or household fixed effects (B). Estimates of infant mortality also include a dummy for multiple births. Estimates of primary education also include dummies for relationship to household head. Standard errors in parentheses, clustered by country-year-of-birth. Number of countries $=27$. DV $=$ dependent variable. ${ }^{*} p<.1$.

${ }^{* *} p<.05$.

${ }^{* * *} p<.01$ 
Figures $1 A$ and $1 B$ show the magnitude of these conditional effects more clearly. In each graph the sloped line represents the predicted marginal effects of democracy on infant mortality at all levels of urbanization included in the sample, with the gray area around it showing the 95\% confidence interval..$^{20}$ Figure $1 A$ shows the marginal effects for urban residents, and figure $1 B$ shows the same for rural residents. These graphs show that for urbanites democracy has no significant effect on infant mortality, at any level of urbanization. By contrast, for rural residents democracy has a significant negative effect on infant mortality, up to a level of urbanization of $29 \%$.

A majority of the children in the infant mortality sample were born in countries where the level of urbanization was less than $30 \%$ (summary statistics are included in table A.2). Taking into consideration the distribution of urbanization for the rural subsample, the marginal effects presented in figure $1 B$ imply that the effect of democracy on infant mortality is significant for half of the sampled rural residents. Most importantly, these graphs show that in countries with large rural majorities (where those living in rural areas make up more than $70 \%$ of the population), there is a clear rural bias in the effects of democracy. In such contexts, democracy leads to a statistically significant reduction in infant mortality for rural residents but has no statistically significant effect for urbanites. As urbanization increases beyond 29\%, however, this rural bias disappears.

Panel B in table 2 contains the results from estimates of equation (2) for which the outcome of interest is access to primary education. The pattern is much the same as for infant mortality. Running the estimates on the entire sample highlights a strong interaction effect, whereby the positive effect of democracy on access to primary education is decreasing in the level of urbanization. As with infant mortality, this fits the theoretical expectations, but again the average effects obscure important differences across urban and rural areas. Models 9 and 11 show that there is no statistically significant conditional effect for urbanites, whereas for rural residents the positive effect of democracy on access to primary school is significantly decreasing in urbanization.

The magnitudes of these conditional effects are shown in the lower panels of figure 1. For the urban subsample, figure $1 C$

20. These graphs were created using the code provided by Hainmueller, Mummolo, and Xu (2016). The stacked histograms at the bottom of each panel show the distribution of urbanization in the sample, with the dark and light portions of the histogram bars showing the distribution of democracy to nondemocracy, respectively. These demonstrate that the estimates of conditional effects have common support and do not rely on excessive extrapolation. Marginal effects from a binning estimator provide some support for the assumption of linear interaction effects for the rural subsample and are presented in fig. B.1 (figs. B.1-B.8 are available online). demonstrates that the effect of democracy on access to primary education never reaches standard levels of statistical significance, at any level of urbanization. For rural residents, though, figure $1 D$ shows that in countries with big rural majorities democracy has a large, statistically significant, and positive effect on access to primary education. This effect decreases with urbanization and loses statistical significance once the proportion of urbanites in the population becomes greater than $28 \%$. Close to $48 \%$ of respondents in the education sample were living in countries with urbanization levels of less than $28 \%$ when they reached primary school age, and a majority of the rural subsample reached primary school age in contexts where democracy is estimated to have a significant effect on their likelihood of going to school.

Again, though, what is most important here is that in countries with large rural majorities, these results demonstrate a clear rural bias in the effect of democracy on access to basic education. Where the rural share of the population was greater than $71 \%$, democracy had a significantly positive effect on access to primary education for rural residents but not urbanities. As the level of urbanization increases, this rural bias reduces as the incentives to satisfy rural voters dissipate. Together these results provide support for the theoretical argument that democracy in Africa creates incentives for governments to increase the provision of basic services to rural residents in order to court the votes of the rural majority.

In contrast to the unconditional effects presented in table 1 , there is a noticeable difference in the conditional effects when the Multiparty variable is used in place of the Democracy measure. For the estimates of infant mortality in panel A of table 2, there is no significant interaction between multiparty elections and urbanization, whether estimated for the full sample or separately for the urban and rural subsamples. For the estimates of access to primary education in panel $\mathrm{B}$ of table 2 , there appears to be a significant interaction between multiparty elections and urbanization when estimated for both the urban and rural subsamples. However, it is worth noting that binning estimates demonstrate that there are not statistically different effects of multiparty elections at typical low and high values of urbanization for the urban subsample (see panel c of fig. B.2). What these results suggest then is that, in the absence of an even electoral playing field, multiparty elections may indeed be insufficient to generate incentives for incumbents to fully pursue the types of electoral strategies that lead to rural bias.

\section{ALTERNATIVE EXPLANATIONS}

This section considers two alternative explanations for the results presented above: first, that the estimates of the impact of democracy are simply picking up pretrends in education and health outcomes and, second, that the different effects for 
A

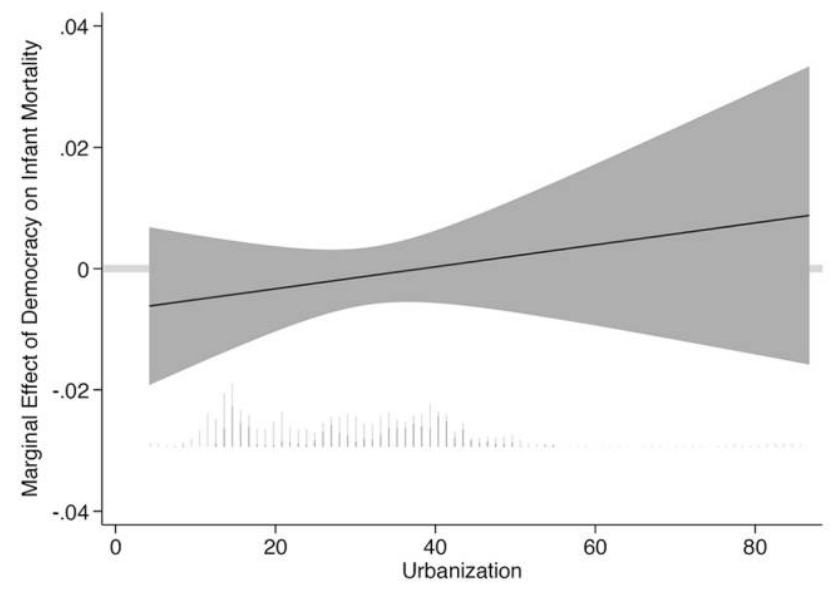

C

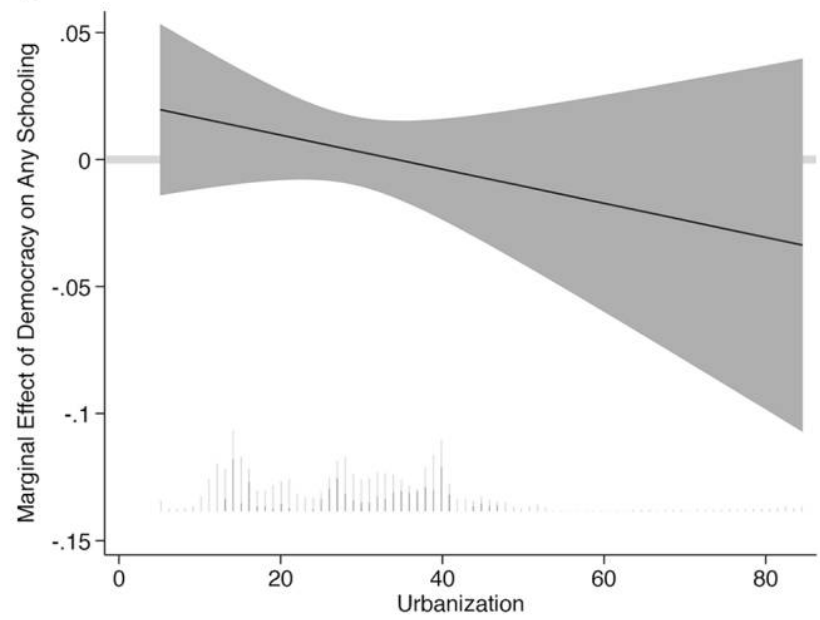

B

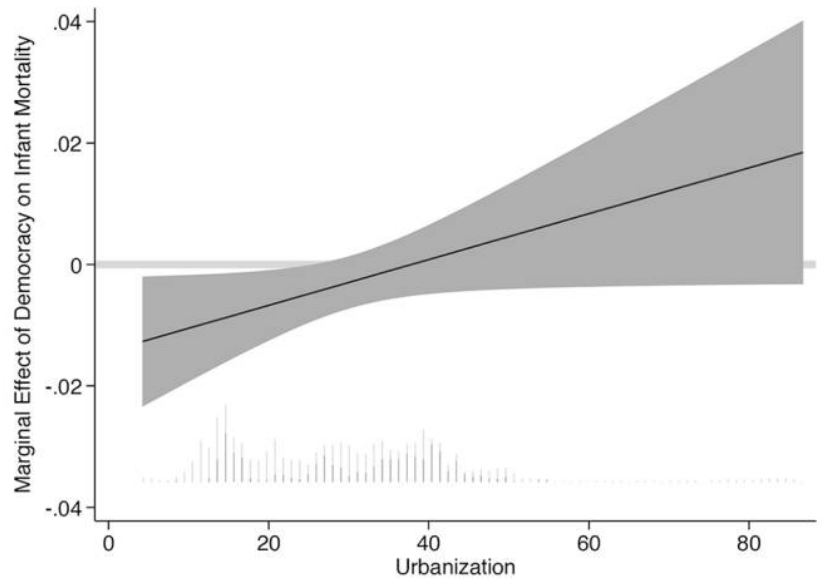

D

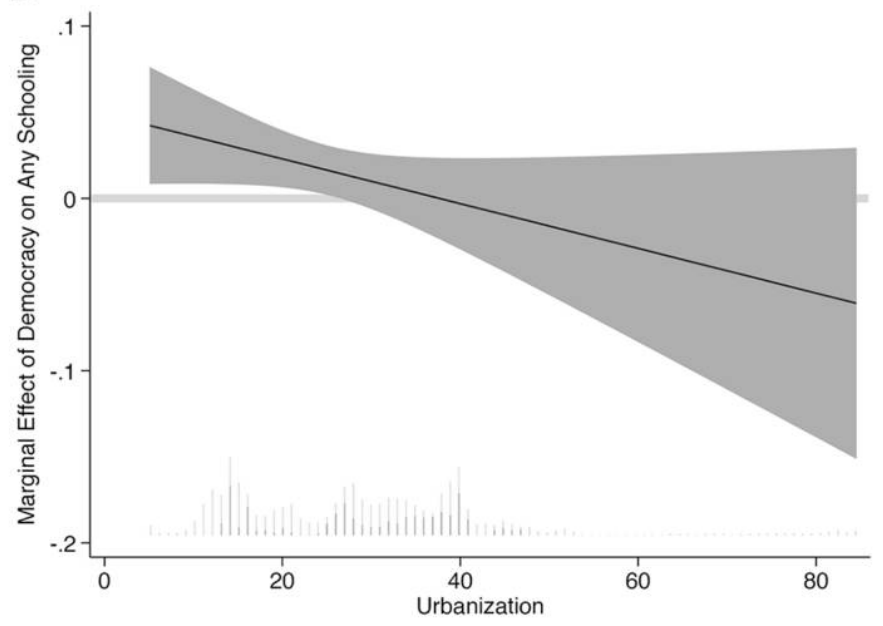

Figure 1. Marginal effects of democracy on basic service provision. Sloped lines show marginal effects of democracy on the probability of a child dying before reaching her first birthday $(A, B)$ and a child ever having been to school $(C, D)$. Gray areas are $95 \%$ confidence intervals. $A$ and $C$ show effects for urban residents; $B$ and $D$ show effects for rural residents. Stacked histograms show the distribution of urbanization, with the dark and light portions of the bars showing the distribution of democracy to nondemocracy, respectively.

urban and rural residents are driven by coethnic favoritism in resource distribution.

\section{Pretrends in health and education}

A possible concern is that the estimates of the impact of democracy are just picking up pretrends in infant mortality rates and access to primary education. As such, the effects we are attributing to the introduction of democracy could simply reflect long-term positive trends in access to services across Africa, since in the aggregate basic health and education outcomes have been improving over time, irrespective of regime type. I investigate this possibility by running falsification tests using a series of placebo treatment variables alongside the democracy variable. ${ }^{21}$

21. A similar strategy is pursued by Franck and Rainer (2012).
For the infant mortality estimates, these placebo variables are constructed by shifting the Democracy variable forward by between 1 and 6 calendar years. As such, the placebo estimates the impact on infant survival of a country becoming democratic 1-6 years after a child's birth. Since there is no reason to expect that the positive effects of democracy should be realized 1-6 years before a democratic transition, in this case large and significant negative coefficients on the placebo variables would suggest that pretrends in infant mortality rates could be driving the results, whereas small and insignificant coefficients would allay such a concern.

I pursue a similar strategy for the education estimates, constructing the placebo variables by shifting the Democracy variable forward by between 1 and 6 calendar years. These placebo variables therefore estimate the impact on access to primary education of a country becoming democratic in the 1-6 years after a child passes primary school age. Since it is 
reasonable to assume that primary education attainment is determined during a child's primary school age years, rather than after, large and statistically significant positive coefficient on the placebo variables would suggest that pretrends in access to primary education could be driving the results, whereas small and insignificant coefficients would provide confidence that the positive education effects being attributed to democracy are not spurious.

Section B.6 of the appendix contains results from a series of falsification tests, in which the models in table 1 were reestimated with the placebo variables included. In comparison to the coefficients for the Democracy variable, all of the coefficients for the placebo version are smaller and statistically insignificant. This provides confidence that the results reported above reflect the effect of the introduction of democratic elections, rather than the effects of long-term trends in health and education outcomes.

\section{Coethnic favoritism}

Recent work has provided evidence of coethnic favoritism in the provision of basic education and health services in Africa (Franck and Rainer 2012; Kramon and Posner 2016). This raises the possibility that the evidence for rural bias could be misleading if the different effects for urban and rural residents actually reflect coethnic favoritism in resource distribution. This type of spurious conclusion could arise if ethnic groups are unevenly distributed across urban and rural areas and if predominantly rural groups are more likely to gain access to power under democracy. Intuitively, high levels of ethnic heterogeneity across Africa means this is unlikely, because in no country are there obviously distinct "rural" and "urban" ethnic groups. Nonetheless, I investigate this alternative explanation using information on self-reported ethnicity included in a subset of the DHS surveys.

Information on ethnicity is available for 19 of the 27 countries included in the foregoing analyses and is used to code a Coethnic Leader variable that captures the effect of being from the same ethnic group as the president. For the infant mortality analysis, this variable is coded 1 if a child was born in a year in which one of her coethnics was in power and 0 otherwise. Analogous to the Democracy variable, for the education analysis Coethnic Leader captures the proportion of an individuals' primary school age years spent with a coethnic as president. Information on the ethnic identities of African leaders up to 2002 comes from Fearon, Kasara, and Laitin (2007) and has been updated to cover the years included in the sample. To evaluate whether the main results are proxying for the distribution of resources on the basis of ethnicity, I reestimate equations (1) and (2) with the Coethnic
Leader variable included in all of the models. The results are presented in section B.7 of the appendix.

It is important to note that even without controlling for coethnicity, limiting the sample to countries for which there is information on ethnicity alters the main results; although the direction of the coefficients on the Democracy variable remains the same, the coefficients no longer all reach the same levels of statistical significance. As such, it is necessary to be cautious in making conclusions about the impact of including the Coethnic Leader variable. Importantly, though, running the baseline estimates on the reduced sample shows that any weakening in the results is driven by the sample reduction, rather than the inclusion of the Coethnic Leader control.

The general pattern of the average effects of democracy on both infant mortality and access to primary education seen in the main analysis holds for the restricted sample, and the coefficients are largely unaffected by the inclusion of the Coethnic Leader variable. Similarly, for infant mortality the patterns of the conditional effects remain just as they were when estimated using the full sample, although again the sample restriction means that the coefficients are no longer statistically significant. This is the case irrespective of whether the Coethnic Leader variable is interacted with urbanization. For the estimates of primary education, the estimates of the conditional effects are significant at standard levels, although here the pattern differs slightly from the main analysis. Specifically, in this case the conditional effects of democracy appear to hold for both the urban and the rural subsamples, rather than just for rural households. Again, though, it is worth noting that this is a function of the reduced sample and is not due to the inclusion of the Coethnic Leader variable. As such, the most important implication is that any effects of coethnic favoritism are not driving the results in the main analysis.

\section{CONCLUSION}

This research investigates the relationship between democracy and basic health and education outcomes across Africa, using individual-level data across 27 countries to assess whether meaningful electoral competition affects the probability of children dying before age 1 and of attending primary school. It also examines whether these effects vary across urban as opposed to rural areas. The analysis is motivated by a straightforward theoretical claim, that while urban bias under autocracies rendered rural areas relatively deprived, the electoral incentives introduced by democracy mean that rural voters can no longer be ignored. Since in most African countries a majority of the population lives in rural areas, this implies that African governments that are subject to meaningful electoral constraints have incentives to pursue policies that benefit the interests of this rural majority, such that rural areas should 
benefit relatively more from democracy in terms of any positive changes resulting from increased public goods provision.

The results provide strong evidence to support this claim. Children born in democracies are less likely to die before their first birthdays than those born in nondemocracies, and individuals who reach primary school age subsequent to the introduction of meaningful democratic elections have a significantly higher probability of attending primary school than those who spend their primary school age years in nondemocratic contexts. Moreover, there is evidence of a clear rural bias in the impact of democracy on basic services; the effects of democracy on education and health are both larger and stronger for rural residents than they are for urbanites. Further still, the analyses show that the extent of this rural bias is conditional on and decreasing in the level of urbanization, thereby supporting what is arguably a unique observable implication of the theoretical claim.

Certainly, these results do not tell the whole story about the relationship between democracy and the provision of basic services in Africa. To fully understand this relationship requires consideration of the precise policy mechanisms through which democracy affects basic services. For example, as Harding and Stasavage (2014) have shown, the effect is likely to work through specific policies such as the abolition of user fees. Future work should investigate these policy mechanisms further. Nevertheless, the results provide an important insight into how the effects of democracy are distributed in Africa: with regard to basic services, democracy is good for rural residents. Moreover, these results contribute to how electoral politics in Africa are understood more generally. Although fraud, ethnic mobilization, and clientelism are certainly important issues in African elections, evidence of a rural bias in the effect of democracy on basic health and education outcomes supports the claim that African governments also seek to construct electoral majorities through the provision of basic services.

\section{ACKNOWLEDGMENTS}

I am grateful to David Stasavage, Leonard Wantchekon, Joshua Tucker, Oeindrila Dube, Alex Scacco, Staffan Lindberg, Kate Baldwin, Joachim Wehner, Nahomi Ichino, Kimuli Kasara, and seminar participants at the London School of Economics and Nuffield College, University of Oxford, for comments on previous versions of this manuscript. I also thank anonymous reviewers for their feedback.

\section{REFERENCES}

Bates, Robert. 1981. Markets and States in Tropical Africa: The Political Basis of Agricultural Policies. Berkeley: University of California Press.
Bates, Robert H., and Steven A. Block. 2013. "Revisiting African Agriculture: Institutional Change and Productivity Growth.” Lournal of Politics 75 (2): 372-84.

Beck, T., G. Clarke, A. Groff, P. Keefer, and P. Walsh. 2001. "New Tools in Comparative Political Economy: The Database of Political Institutions." World Bank Economic Review 15 (1): 165-76.

Besley, Tim, and Masayuki Kudamatsu. 2006. "Health and Democracy." American Economic Review 96 (2): 313-18.

Brown, David S., and Ahmed Mushfiq Mobarak. 2009. "The Transforming Power of Democracy: Regime Type and the Distribution of Electricity." American Political Science Review 103 (2): 193-213.

Bueno de Mesquita, Bruce, James D. Morrow, Randolph Siverson, and Alastair Smith. 2001. "Political Competition and Economic Growth." Journal of Democracy 12 (1): 58-72.

Burgess, Robin, Remi Jedwab, Edward Miguel, Ameet Morjaria, and Gerard Padro i Miquel. 2015. "The Value of Democracy: Evidence from Road Building in Kenya.” American Economic Review 105 (6): 1817-51.

Cheibub, Jose Antonio, and Adam Przeworski. 1999. "Democracy, Elections, and Accountability for Electoral Outcomes.” In Adam Przeworski, Susan Carol Stokes, and Bernard Manin, eds., Democracy, Accountability, and Representation. Cambridge: Cambridge University Press.

Cutler, David M., and Adriana Lleras-Muney. 2006. "Education and Health: Evaluating Theories and Evidence.” Working paper no. 12352, National Bureau of Economic Research, Cambridge, MA. http://www.nber.org /papers/w12352.

Fearon, James D., Kimuli Kasara, and David D. Laitin. 2007. "Ethnic Minority Rule and Civil War Onset.” American Political Science Review 101 (1): 187-93.

Franck, Raphael, and Ilia Rainer. 2012. "Does the Leader's Ethnicity Matter? Ethnic Favoritism, Education, and Health in Sub-Saharan Africa." American Political Science Review 106 (2): 294-325.

Glaeser, Edward L., Giacomo A. M. Ponzetto, and Andrei Shleifer. 2007. "Why Does Democracy Need Education?" Lournal of Economic Growth 12 (2): 77-99.

Hainmueller, Jens, Jonathan Mummolo, and Yiqing Xu. 2016. "How Much Should We Trust Estimates from Multiplicative Interaction Models? Simple Tools to Improve Empirical Practice." SSRN. https://doi.org /10.2139/ssrn.2739221.

Harding, Robin. 2015. "Attribution and Accountability: Voting for Roads in Ghana." World Politics 67 (4): 656-89.

Harding, Robin, and David Stasavage. 2014. "What Democracy Does (and Doesn't) Do for Basic Services: School Fees, School Inputs, and African Elections." Journal of Politics 76 (1): 229-45.

Kramon, Eric, and Daniel N. Posner. 2016. "Ethnic Favoritism in Primary Education in Kenya." Quarterly Journal of Political Science 11 (1): 1-58.

Kroth, Verena, Valentino Larcinese, and Joachim Wehner. 2016. “A Better Life for All? Democratization and Electrification in Post-Apartheid South Africa." Lournal of Politics 78 (3): 774-91.

Kudamatsu, Masayuki. 2012. "Has Democratization Reduced Infant Mortality in Sub-Saharan Africa? Evidence from Micro Data." Journal of the European Economic Association 10 (6): 1294-317.

Lake, David A., and Matthew A. Baum. 2001. "The Invisible Hand of Democracy: Political Control and the Provision of Public Services." Comparative Political Studies 34 (6): 587-621.

Larreguy, Horacio, and John Marshall. 2017. "The Effect of Education on Civic and Political Engagement in Nonconsolidated Democracies: Evidence from Nigeria." Review of Economics and Statistics 99 (3): 387-401.

Min, Brian. 2015. Power and the Vote: Elections and Electricity in the Developing World. Cambridge: Cambridge University Press.

Nathan, Noah L. 2016. "Local Ethnic Geography, Expectations of Favoritism, and Voting in Urban Ghana.” Comparative Political Studies 49 (14): 1896-929. 
Ross, Michael. 2006. "Is Democracy Good for the Poor?" American Journal of Political Science 50:860-74.

Rutstein, Shea O. 2008. "The DHS Wealth Index: Approaches for Rural and Urban Areas." DHS working paper, USAID.

Stasavage, D. 2005. "Democracy and Education Spending in Africa." American Journal of Political Science 49 (2): 343-58.
Stokes, Susan C., Thad Dunning, Marcelo Nazareno, and Valeria Brusco. 2013. Brokers, Voters, and Clientelism: The Puzzle of Distributive Politics. Cambridge: Cambridge University Press.

Weghorst, Keith R., and Staffan I. Lindberg. 2013. "What Drives the Swing Voter in Africa." American Journal of Political Science 57 (3): $717-34$. 